\title{
JEKK
}

Jurnal Epidemiologi Kesehatan Komunitas

5 (1), 2019, 32-37

\section{Hubungan Status Merokok dengan Kejadian Ulkus Diabetikum pada Laki-Laki Penderita Diabetes Melitus}

\author{
Shofia Aji Hidayatillah", Heri Nugroho**, Sakundarno Adi*** \\ "Magister Epidemiologi Universitas Diponegoro, ${ }^{* *}$ Bagian Penyakit Dalam Fakultas Kedokteran Undip, \\ ${ }^{* * *}$ Sekolah Pascasarjana Undip
}

\begin{abstract}
Background: The incidence of diabetic ulcers in Indonesia is $12 \%$ and the risk of diabetic ulcers is 55.4\% .10 Cases of diabetic ulcers and gangrene in Indonesia are the most known cases in hospitals. Mortality due to ulcers and gangrene ranges from 17-23\%, while the amputation rate starts at 15$30 \%$. Diabetic ulcers are the most common complication in people with Diabetes Mellitus (DM). The purpose of this study is to study the relationship of smoking with the incidence of diabetic ulcers in men with DM. The study design in this study is case control.

Methods: This research was conducted in the outpatient and inpatient installation of RSUD dr. Loekmono Hadi Kudus Regency and RSI Sunan Kudus on August - September 2019. The population in this study were men with DM who received 25-80 years who had a health examination at dr. Loekmono Hadi Kudus Regency and RSI Sunan Kudus. A total of 35 cases and 35 controls were selected using consecutive sampling. Data were analyzed with chi square.
\end{abstract}

Result: The results showed a significant relationship between smoking and the incidence of diabetic ulcers in men with DM $(\mathrm{p}=0.030 ; 95 \% \mathrm{CI}=1,235-8,997)$ and physical activity $(\mathrm{p}=0.015 ; 95 \% \mathrm{CI}$ $=1,401-10,590)$.

Conclusion : In this study, smoking and physical activity are related with the incidence of diabetic ulcers in men who are diabetic patients.

Keywords: diabetes mellitus; male; smoking; diabetic ulcer.

*Penulis korespondensi, shofiahidayatillah@gmail.com 


\section{Pendahuluan}

Ulkus diabetikum merupakan luka terbuka pada permukaan kulit yang disebabkan adanya kelainan pada saraf (neuropati), kelainan pembuluh darah, dan kemudian adanya infeksi. ${ }^{1}$ Gejala neuropati menyebabkan hilang atau berkurangnya rasa nyeri di kaki, sehingga apabila penderita mendapat trauma akan sedikit atau tidak merasakan nyeri dan berdampak luka pada kaki. ${ }^{2}$ Pemeriksaan fisik pada penderita dengan ulkus diabetes dibagi menjadi 3 bagian yaitu 1) pemeriksaan ulkus dan keadaan ekstremitas, 2) penilaian kemungkinan insufisiensi vaskuler, 3) penilaian kemungkinan neuropati perifer. ${ }^{3}$

Ulkus diabetikum menjadi faktor penyebab utama terjadinya amputasi ekstremitas bawah pada kaki pasien Diabetes mellitus (selanjutnya disebut DM). ${ }^{4}$ Prevalensi ulkus diabetikum secara global sebanyak $6,3 \%$ dengan prevalensi tertinggi di Belgia sebesar 16,6\%; Kanada sebesar 14,8\%; USA sebesar 13\%; Afrika sebesar 7,2\%; Asia sebesar 5,5\%; Eropa sebesar 5,1\%; Oceania 3\%; dan terendah di Australia sebesar 1,5\%. ${ }^{5}$ Di Indonesia kejadian ulkus diabetikum sebesar $12 \%$ dan resiko ulkus diabetikum sebesar 55,4\%. ${ }^{6}$ Penderita DM dengan gangguan sirkulasi gangren, ulkus di Instalasi Rawat Inap RSUD dr. Loekmono Hadi Kabupaten Kudus pada tahun 2017 sebanyak 393 kasus dan tahun 2018 sebanyak 361 kasus. DM dengan gangguan sirkulasi perifer, gangren, ulkus merupakan bagian dari 10 besar penyakit yang dirawat di RSUD dr. Loekmono Hadi Kabupaten Kudus.

Berbagai faktor yang terkait dengan kejadian ulkus diabetik pada penderita DM tipe 2 yaitu umur, jenis kelamin, lama menderita DM, obesitas, hipertensi, kadar gula darah, kebiasaan merokok, perawatan kaki, penggunaan alas kaki, riwayat ulkus sebelumnya, dan kepatuhan diet. ${ }^{7,8}$

Merokok masih merupakan penyebab masalah kesehatan pada saat ini. WHO memperkirakan pada tahun 2020 penyakit yang berkaitan dengan rokok akan menjadi masalah kesehatan utama di berbagai negara. Berdasarkan data Global Adult Tobacco Survey (GATS) Tahun 2010, Indonesia menduduki posisi pertama dengan prevalensi perokok aktif tertinggi, yaitu $67 \%$ pada laki-laki dan $2,7 \%$ pada wanita. $^{9}$

Asap rokok juga terkandung gas $\mathrm{CO}$ yang mempunyai afinitas yang jauh lebih tinggi terhadap $\mathrm{Hb}$ dibandingkan $\mathrm{O}_{2}$. Kerusakan pembuluh darah tersebut dapat berakibat pada terhambatnya proses penyernbuhan bila terjadi luka dan berisiko terhadap terjadinya infeksi dan amputasi. ${ }^{10}$ Ulkus diabetikum merupakan masalah yang penting karena memiliki dampak yang besar bagi penderita DM. Penelitian tentang hubungan merokok dengan penderita laki-laki DM masih jarang dilakukan. Oleh karena itu, peneliti berkeinginan melakukan penelitian tentang hubungan merokok dengan penderita laki-laki DM menggunakan desain studi kasus kontrol. Tujuan penelitian ini untuk mengetahui hubungan riwayat merokok dengan kejadian ulkus diabetikum pada laki-laki penderita DM.

\section{Metode}

Jenis penelitian yang dilakukan adalah studi observasional analitik dengan desain studi kasus kontrol. Variabel terikat pada penelitian ini adalah kejadian ulkus diabetikum pada lakilaki penderita DM. Variabel bebas dalam penelitian ini usia, status merokok, status IMT, dan tingkat aktivitas fisik.

Populasi target pada penelitian ini adalah seluruh penduduk dengan diagnosis DM di Kabupaten Kudus, Demak, Pati, dan Jepara, Provinsi Jawa Tengah. Populasi studi kasus pada penelitian ini adalah semua pasien lakilaki dengan diagnosis DM yang menderita Ulkus diabetikum dan dirawat di RSUD dr. Loekmono Hadi Kabupaten Kudus dan RSI Sunan Kudus. Populasi studi kontrol pada penelitian ini adalah semua pasien laki-laki dengan diagnosis DM yang tidak menderita Ulkus diabetikum dan dirawat di RSUD dr. Loekmono Hadi Kabupaten Kudus dan RSI Sunan Kudus.

Sampel dengan diagnosis DM yang menderita ulkus diabetikum dimasukkan sebagai sampel kelompok kasus sedangkan sampel dengan diagnosis DM yang tidak menderita ulkus diabetikum dimasukkan sebagai sampel kelompok kontrol dengan pertimbangan kriteria inklusi (usia 25 tahun 
sampai dengan 80 tahun dan bersedia menjadi responden dengan mengisi informed consent) dan kriteria eksklusi (dalam kondisi syok, sepsis, dan kondisi lainnya, sehingga tidak bisa untuk diwawancarai).

Penelitian ini dilakukan di instalasi rawat jalan dan rawat inap RSUD dr. Loekmono Hadi Kabupaten Kudus dan RSI Sunan Kudus pada bulan Agustus-September 2019. Pengambilan data bersumber dari rekam medis dan instrumen kuesioner. Instrumen penelitian pada variabel tingkat aktivitas fisik yang digunakan adalah kuesioner GPAQ (Global Physical Activity Questionnaire). Variabel status merokok adalah kebiasaan merokok 5 tahun terakhir responden sebelum di diagnosis ulkus diabetikum (kasus), sampai saat wawancara (kontrol). Sebanyak 35 kasus dan 35 kontrol dipilih menggunakan consecutive sampling. Pengolahan dan analisa data dilakukan dengan program SPSS meliputi analisis univariat dan bivariat dengan uji chi square.

Penelitian ini sudah mendapatkan ethical clearance dari Komisi Etik Penelitian Kesehatan (KEPK) Fakultas Kedokteran Universitas Diponegoro Semarang dengan nomor 410/EC/FK-RSDK/IX/2019.

\section{Hasil}

Jumlah responden penelitian sebanyak 70 orang, terdiri 35 orang penderita DM dengan ulkus diabetikum sebagai kasus dan 35 orang penderita DM tanpa ulkus diabetikum sebagai kontrol.

Tabel 1. Karakteristik Subyek Penelitian

\begin{tabular}{lrrrr}
\hline \multirow{2}{*}{ Variabel } & \multicolumn{2}{c}{ Kasus } & \multicolumn{2}{c}{ Kontrol } \\
\cline { 2 - 5 } & n & $\mathbf{( \% )}$ & n & $\mathbf{( \% )}$ \\
\hline Umur & & & & \\
\hline$\geq 40$ tahun & 32 & 91,4 & 33 & 94,3 \\
$<40$ tahun & 3 & 8,6 & 2 & 5,7 \\
\hline Status IMT & & & & \\
\hline Obesitas & 13 & 37,1 & 17 & 48,6 \\
$\left(\geq 23 \mathrm{~kg} / \mathrm{m}^{2}\right)$ & & & & \\
$\quad$ Tidak Obesitas & 22 & 62,9 & 18 & 51,4 \\
\hline Status Merokok & & & & \\
\hline Ya & 25 & 71,4 & 15 & 42,9 \\
Tidak & 10 & 28,6 & 20 & 57,1 \\
\end{tabular}

\begin{tabular}{crrrr}
\hline Variabel & \multicolumn{2}{c}{ Kasus } & \multicolumn{2}{c}{ Kontrol } \\
\cline { 2 - 5 } & $\mathbf{n}$ & $\mathbf{( \% )}$ & $\mathbf{n}$ & $\mathbf{( \% )}$ \\
\hline \multicolumn{2}{l}{ Tingkat Aktivitas Fisik } & & & \\
\hline$<600$ MET & 26 & 74,3 & 15 & 42,9 \\
$\geq 600$ MET & 9 & 25,7 & 20 & 57,1 \\
\hline
\end{tabular}

Tabel 1 menunjukkan bahwa responden yang berumur $\geq 40$ tahun lebih banyak pada kelompok kontrol (94,3\%) dibandingkan dengan kelompok kasus $(91,4 \%)$.

Responden yang status IMT dengan obesitas $(\geq 23)$ lebih banyak pada kelompok kontrol $(48,6 \%)$ dibanding dengan kelompok kasus $(37,1 \%)$. Sedangkan responden yang memiliki status merokok lebih banyak pada kelompok kasus $(71,4 \%)$ dibanding dengan kelompok kontrol $(42,9 \%)$.

Pada variabel tingkat aktivitas fisik, responden yang tidak sesuai anjuran WHO (World Health Organization) <600 MET lebih banyak pada kelompok kasus $(74,3 \%)$ dibandingkan kelompok kontrol (42,9\%). Secara lengkap analisis univariat disajikan pada Tabel 1.

Analisis bivariat dilakukan untuk mengetahui adanya hubungan antara variabel bebas dengan variabel terikat dengan menggunakan analisis statistik dengan uji chisquare (x2) dan memperhatikan nilai $\mathrm{p}<0,05$ yang menunjukkan hubungan bermakna antar variabel. Besarnya nilai odds ratio $(O R>1)$ dengan CI 95\% untuk mengetahui apakah variabel umur, status IMT, status merokok, dan aktivitas fisik yang diuji merupakan faktor yang berhubungan atau bukan faktor yang berhubungan dengan kejadian ulkus diabetikum.

Tabel 2. Hasil Analisis Bivariat terhadap Kejadian Ulkus Diabetikum pada Laki-Laki Penderita DM

\begin{tabular}{lccc}
\hline \multicolumn{1}{c}{ Variabel } & OR & $\mathbf{9 5 \%}$ IK & $\boldsymbol{p}$ \\
\hline $\begin{array}{l}\text { Memiliki } \\
\text { status merokok }\end{array}$ & 3,33 & $1,235-8,997$ & 0,030 \\
$\begin{array}{l}\text { Status IMT } \\
\quad \text { Obesitas }\end{array}$ & 0,865 & $0,301-2,485$ & 1,000 \\
$\begin{array}{l}\text { Usia } \geq 40 \\
\text { tahun }\end{array}$ & 0,646 & $0,101-4,128$ & 0,500 \\
$\begin{array}{l}\text { Tingkat } \\
\text { aktivitas fisik }\end{array}$ & 3,852 & $1,401-10,590$ & 0,015 \\
\hline
\end{tabular}


Pada hasil analisis bivariat, menunjukkan bahwa variabel yang memiliki hubungan signifikan terhadap kejadian ulkus diabetikum yaitu variabel status merokok $(\mathrm{OR}=3,33$ dan $\mathrm{p}$ $=0,030)$ dan tingkat aktivitas fisik $(\mathrm{OR}=3,85$ dan $\mathrm{p}=0,015$ ).

\section{Pembahasan}

Laki-laki penderita DM dengan status merokok memiliki risiko 3,33 kali lebih besar (95\% CI $=1,235-8,997)$ untuk menderita Ulkus Diabetikum dibandingkan laki-laki penderita DM yang tidak memiliki status merokok. Hal ini sesuai dengan penelitian yang dilakukan di Sudan bahwa riwayat merokok berhubungan dengan terjadinya ulkus diabetikum $(\mathrm{p}=$ 0.000). ${ }^{11}$ Sejalan juga dengan penelitian di Pakistan, status merokok mempunyai risiko terjadinya komplikasi makrovaskuler pada penderita DM tipe 2 sebesar 4 kali dibandingkan dengan yang tidak $(\mathrm{aOR}=4.01$, 95\% CI1.49-10.71). ${ }^{12}$

Kebiasaan merokok akibat dari nikotin yang terkandung di dalam rokok akan dapat menyebabkan kerusakan endotel kemudian terjadi penempelan dan agregasi trombosit yang selanjutnya terjadi kebocoran sehingga lipoprotein lipase akan memperlambat lemak darah dan mempermudah timbulnya aterosklerosis. Aterosklerosis berakibat insufisiensi vaskuler sehingga aliran darah ke arteri dorsalis pedis, poplitea, dan tibialis juga akan menurun. ${ }^{13}$ Ulkus diabetikum merupakan komplikasi makrovaskuler yang paling banyak diderita pada penderita DM. Sebanyak $77,8 \%$ penderita ulkus diabetik memiliki riwayat merokok kurang dari 12 batang per hari. ${ }^{14}$

Pada aktifitas fisik, laki-laki penderita DM dengan tingkat aktivitas fisik tidak sesuai anjuran WHO (World Health Organization) $<600$ MET memiliki risiko 3,85 kali lebih besar $(95 \% \mathrm{CI}=1,401-10,590)$ untuk menderita Ulkus Diabetikum dibandingkan laki-laki penderita DM yang tingkat aktivitas fisik sesuai anjuran WHO (World Health Organization $) \geq 600$ MET. Penelitian di Swiss oleh Rocher dikutip oleh Wibisono pada penderita DM dengan neuropati, hasil penelitian olah raga tidak teratur akan terjadi Ulkus diabetika lebih tinggi 4 kali dibandingkan dengan olah raga yang teratur. ${ }^{15}$ Penelitian yang dilakukan oleh Yadav, Tiwari, and Dhanaraj (2008) aktivitas fisik seperti berjalan kaki setidaknya 30 menit perhari dapat menurunkan terjadinya komplikasi seperti timbulnya ulkus diabetikum. ${ }^{16}$

Aktivitas fisik (olah raga) sangat bermanfaat untuk meningkatkan sirkulasi darah, menurunkan berat badan dan memperbaiki sensitivitas terhadap insulin, sehingga akan memperbaiki kadar glukosa darah. ${ }^{17}$

Pada variabel umur $\geq 40$ tahun pada lakilaki penderita DM tidak memiliki hubungan yang bermakna dengan kejadian ulkus diabetikum $(\mathrm{p}=0,500)$. Penelitian yang dilakukan oleh Hastuti (2008) menunjukkan tidak ada hubungan yang bermakna antara umur $\geq 60$ tahun dengan kejadian ulkus diabetika, tapi terdapat hubungan yang bermakna antara umur 56-59 tahun dengan kejadian ulkus diabetikum. ${ }^{8}$ Sedangkan penelitian ini tidak sejalan dengan penelitian yang dilakukan di RSU Anutapura Palu yakni ada hubungan antara usia dengan kejadian ulkus diabetikum $(\mathrm{p}=0,012) .{ }^{18}$ Pada usia tua fungsi tubuh secara fisiologis menurun karena proses aging terjadi penurunan sekresi atau resistensi insulin sehingga kemampuan fungsi tubuh terhadap pengendalian glukosa darah yang tinggi kurang optimal. ${ }^{1}$

Penelitian yang dilakukan di RSUD DR. Moewardi Surakarta bahwa responden dengan usia 41-50 tahun sebanyak 13\%, responden berusia 51-60 tahun dan responden dengan usia >60 tahun sebanyak 20,4\%. ${ }^{19}$ Namun faktor usia bukanlah faktor utama terjadinya ulkus diabetikum karena apabila responden dapat melakukan penatalaksanaan diabetes melitus dengan baik dan memahami tentang penyebab dari terjadinya ulkus kaki diabetikum maka risiko terjadinya komplikasi dapat terminimalisir. ${ }^{20}$

Pada variabel status IMT, laki-laki penderita DM dengan obesitas $\left(\geq 23 \mathrm{~kg} / \mathrm{m}^{2}\right)$ tidak memiliki hubungan yang bermakna dengan kejadian ulkus diabetikum $(\mathrm{p}=1,000)$. Hal ini tidak sejalan dengan penelitian yang dilakukan di RSU Anutapura Palu yakni ada hubungan antara status IMT dengan obesitas 
terhadap kejadian ulkus diabetikum $(\mathrm{p}=0,027){ }^{18}$

Ketidaksesuaian hasil ini dikarenakan pada saat dilakukan penelitian, kondisi responden banyak yang telah mengalami penurunan badan pada saat dirawat. Namun kebanyakan pasien mengakui bahwa mereka pernah mengalami kegemukan. Namun pada saat terkena penyakit DM perlahan-lahan berat badan mereka menurun. Sehingga, pada saat dilakukan penelitian sampel dengan IMT yang berlebih hanya sedikit, sehingga mempengaruhi nilai signifikan. ${ }^{18} \mathrm{Hal}$ ini juga bisa terjadi saat pemilihan responden pada kelompok di kasus dan di kontrol yakni responden yang memiliki riwayat obesitas karena desain penelitian ini menggunakan case control.

Obesitas bisa menjadi faktor yang mengakibatkan menderita penyakit $\mathrm{DM}^{21,22}$ Timbunan lemak akibat badan gemuk atau kondisi obesitas akan menyebabkan resistensi insulin sehingga insulin tidak mampu bekerja dengan optimal dan kadar gula darah naik. Gemuk juga mempermudah timbulnya hipertensi dan lemak darah yang meningkat. Hal ini akan berdampak pada gangguan ginjal, sakit jantung, dan stroke. Orang gemuk yang menderita diabetes lebih mudah terkena komplikasi. ${ }^{23,24}$

\section{Simpulan}

Ada hubungan yang bermakna pada lakilaki penderita DM yang memiliki status merokok dan tingkat aktivitas fisik tidak sesuai anjuran WHO (World Health Organization) $<600$ MET dengan kejadian ulkus diabetikum pada laki-laki penderita DM. Laki-laki penderita DM sebaiknya berupaya untuk mengurangi konsumsi batang rokok tiap hari dan olahraga yang teratur agar terhindar dari komplikasi penyakit DM khususnya risiko kejadian ulkus diabetikum.

\section{Ucapan Terima Kasih}

Terimakasih kepada Direktur RSUD dr. Loekmono Hadi Kabupaten Kudus dan RSI Sunan Kudus dan staf diklat yang telah memberikan izin, dukungan serta motivasi selama melakukan penelitian.

\section{Daftar Pustaka}

1. Waspadji. Buku Ajar Ilmu Penyakit Dalam: Kaki Diabetes. Jakarta: Penerbit Fakultas Kedokteran Universitas Indonesia; 2007. 1911-1914 p.

2. Lipsky BA, Berendt AR, Cornia PB, et al. Infectious Diseases Society of America Clinical Practice Guidelines for The Diagnosis and Treatment of Diabetic Foot Infections. Infect Dis Clin Pract. 2013;21(1):43-45. doi:10.1097/IPC.0b013e318278f3e6

3. J. Doupis, A. Veves. Classification, Diagnosis, and Treatment of Diabetic Foot Ulcers. 2008:20(5):117-26.

4. Frykberg RG, Zgonis T, Armstrong DG, et al. Diabetic Foot Disorders: A Clinical Practice Guideline (2006 revision). J Foot Ankle Surg. 2006;45(5 SUPPL.):1-66. doi:10.1016/S1067-2516(07)60001-5

5. Zhang P, Lu J, Jing Y, Tang S, Zhu D, Bi Y. Global epidemiology of diabetic foot ulceration: a systematic review and metaanalysis. Ann Med. 2017;49(2):106-116. doi:10.1080/07853890.2016.1231932

6. Yusuf S, Okuwa M, Irwan $M$, et al. Prevalence and Risk Factor of Diabetic Foot Ulcers in a Regional Hospital , Eastern Indonesia. Open $J$ Nurs. 2016;6(January):1-10. doi:10.4236/ojn.2016.61001

7. Deribe B. Prevalence and Factors Influencing Diabetic Foot Ulcer among Diabetic Patients Attending Arbaminch Hospital, South Ethiopia. J Diabetes Metab. 2014;05(01). doi:10.4172/21556156.1000322

8. Hastuti RT. Faktor-Faktor Risiko Ulkus Diabetika Pada Penderita Diabetes Mellitus (Studi Kasus di RSUD Dr. Moewardi Surakarta). Tesis. 2008.

9. Suryamin. Global Adult Tobacco Survey (GATS)| Indonesian Report.; 2011.

10. Barnoya J, Glantz SA. Cardiovascular Effects of Secondhand Smoke Nearly as 
Large as Smoking. Circulation. 2005;111:2684-2699.

doi:10.1161/CIRCULATIONAHA.104.49 2215

11. Musa HG, Ahmed ME. Associated Risk Factors and Management of Chronic Diabetic Foot Ulcers Exceeding 6 Months' Duration. Diabet Foot Ankle. 2012;1:1-6.

12. Khuwaja AK, Rafique G, White F AT. Macrovascular Complications and Their Associated Factors Among Persons with Type 2 Diabetes in Karachi , Pakistan - a Multi-Center Study. J Pak Med Assoc. 2004;54(2):60-66.

13. Armstrong DG. Guidelines: Wound Management in Diabetic Foot Ulcers. Presented at the: 2014.

14. Ferawati I. Faktor - Faktor yang Mempengaruhi Terjadinya Ulkus Diabetikum pada Pasien Diabetes Melitus Tipe 2 di RSUD Prof. DR. Margono Soekarjo Purwokerto. 2014.

15. T, Wibisono. Olah Raga dan Diabetes Mellitus Penyakit Dalam RS Adi Husada Undaan Surabaya. Dexa Media. 2004;17(2).

16. Yadav R, Tiwari P, Dhanaraj E. Risk factors and complications of type 2 diabetes in Asians. Crips. 2008;9(2):8-12. http://www.niper.gov.in/risk_factor.pdf.

17. Yunir EM. Terapi Non Farmakologis Pada Diabetes Melitus. Jilid III,. (W, Aru, eds.). Jakarta: FK UI; 2006.

18. Istiqomah, Efendi AA. Faktor Resiko yang Berhubungan dengan Kejadian Ulkus Kaki Diabetik Pada Pasien Diabetes Mellitus di
RSU Anutapura Palu. J Ilm Kedokt. 2014;1(2):1-16.

19. Fauziyah N. Hubungan Pengetahuan Pasien Diabetes Melitus Tipe 2 tentang Risiko terjadinya Ulkus Diabetik dengan Kejadian Ulkus Diabetik di RSUD DR.Moewardi. Naskah Publ. 2012.

20. Husniawati N, Kunci K. Faktor-Faktor Yang Berhubungan Dengan Kejadian Ulkus Kaki Diabetes Mellitus Di Klinik Diabetes Mellitus Tahun 2015. 2015;7(September):1-6.

21. Tandra H. Segala Sesuatu Yang Harus Anda Ketahui Tentang Diabetes. Jakarta: PT. Gramedia Pustaka Utama.; 2008.

22. Sugianto, Hadisaputro, S., Supriharti, Munasik, Adi, M.S. 2018. Faktor-Faktor yang Berpengaruh terhadap Kejadian Diabetes Mellitus Tipe 2 pada Wanita Usia Subur (WUS) di RSUD Kota Madiun. Jurnal Epidemiologi Kesehatan Komunitas, 3(2):80-89.

23. Whyuningsih, S., Nugroho, H., Suhartono, Hadisaputro, S., Adi, M.S., 2016. Faktor Risiko Kejadian Stroke Iskemik pada Penderita Diabetes Mellitus Tipe 2 (Studi Kasus di RSUP Dr. Kariadi Semarang, Jurnal Epidemiologi Kesehatan Komunitas, i(1): 25-31.

24. Sandra, T., Sofro, M.A.U, Suhartono, Martini, Hadisaputro, S., 2016. FaktorFaktor Risiko Kejadian Kaki Diabetik pada Penderita Diabetes Mellitus Tipe 2 (Studi Kasus Kontrol di RSU. Dr. M. Jamil Padang). Jurnal Epidemiologi Kesehatan Komunitas, 1(2): 48-60. 